\title{
A Model to Investigate Preference for Use of Gamification in a Learning Activity
}

Justin Filippou

School of Business IT \& Logistics

RMIT University

Melbourne, Australia

justin.filippou@rmit.edu.au

\section{Christopher Cheong}

School of Business IT \& Logistics

RMIT University

Melbourne, Australia

\section{France Cheong}

School of Business IT \& Logistics

RMIT University

Melbourne, Australia

\section{Abstract}

Applying the engaging and motivating aspects of video games in non-game contexts is known as gamification. Education can benefit from gamification by improving the learning environment to make it more enjoyable and engaging for students. Factors that influence students' preference for use of gamification are identified. Students are surveyed on their experiences of playing a gamified quiz, named Quick Quiz, during class. Quick Quiz features several gamification elements such as points, progress bars, leader boards, timers, and charts. Data collected from the survey is analysed using Partial Least Squares. Factors including 'usefulness', 'preference for use', 'knowledge improvement', 'engagement', 'immersion' and 'enjoyment' were found to be significant determinants. Students were found to have a preference for use for gamification in their learning environment.

Keywords gamification, student engagement, learning and teaching, higher education

\section{Introduction}

Education is a cornerstone of a society that produces informed and intelligent people. As the demography becomes more diverse, the way in which learning and teaching is delivered needs to evolve with the changing demographic of students. An important aspect to consider in this change is ensuring that the learning environment is engaging. Engagement as a construct consists of behaviour, emotion and cognition (Fredricks, Blumenfeld, \& Paris, 2004; Lamborn, Newmann, \& Wehlage, 1992). If students pay attention to class activities, are interested in the material and are willing to invest in their learning, it can be said they are engaged. There are various ways in which learning can be delivered in accordance with these constructs, and thus made more engaging, with one such approach being the use of games for educational purposes. When games are used as the vehicle for a learning activity, this is referred to as Game-based Learning (GBL) (Prensky, 2001). The appealing aspect of games is that they are fun and enjoyable to use, thus, replicating these experiences for learning is expected to lead to improvements in student engagement. Students also find games and simulations to be more interesting as compared to traditional class activities (Randel, Morris, 
Wetzel, \& Whitehill, 1992). Currently, digital learning environments, which are the systems used to carry out learning activities, are struggling to maintain engagement in part due to low levels of interactivity (QUT, 2014), which is cause for concern as lower levels of engagement can lead to reduced academic performance (Kuh, Cruce, Shoup, Kinzie, \& Gonyea, 2008).

The types of games used in GBL can be divided into two categories: commercial and serious games (Connolly, Boyle, MacArthur, Hainey, \& Boyle, 2012). Commercial games are those that are designed primarily for entertainment purposes. However, they are able to be used for learning when used in a controlled way. For example, Minecraft is a game where players mine blocks of resources and use them to build structures. The game was built for fun, yet it can be used to teach students problem solving skills by giving them building challenges to solve (Bos, Wilder, Cook, \& O'Donnell, 2014; Risberg, 2015). Alternatively, serious games are designed and built with the primary intention to educate albeit in an entertaining way (Djaouti, Alvarez, Jessel, \& Rampnoux, 2011). For example, a game called "Kernel Panic" visually represents computer science concepts such as pointers and data manipulation as 3D objects which the player can interact with (Muratet, Torguet, Jessel, \& Viallet, 2009). While using both categories of games for learning can be effective, there are some limitations. Firstly, a commercial game may not always be easy to align with learning objectives. Secondly, developing a serious game from scratch can be costly for most educators or even institutions. A third option can be used to overcome these limitations, which is called gamification.

Gamification is the process of using game elements and thinking and applying these aspects to traditionally non-game contexts (Deterding, Dixon, Khaled, \& Nacke, 2011; Kapp, 2012; Zichermann \& Cunningham, 2011). One benefit to using gamification is that it does not require an implementation of a fully 3D environment to be effective. Rather, only the essential aspects of what makes playing games enjoyable is required. Gamified learning activities can also be constructed with learning in mind from the beginning and so it is possible to balance learning and fun more effectively than entertainment or serious games alone. While studies have investigated the use of gamification in the learning environment in general (Hamari, Koivisto, \& Sarsa, 2014), little empirical evaluation has been conducted that focuses on what factors contribute to students accepting a gamified learning activity. Identifying these factors will help instructors make evidence-based choices in the design of both the physical and digital learning environments, and hence improve the likelihood of gamification being used successfully. The research presented henceforth answers the question:

What factors impact students' preference for gamification in learning activities?

To answer this question, a model is developed that is tested against students' use of an in-class gamified learning activity. While it anticipated that all students may benefit from gamification being applied to learning, this research will target undergraduate students as a first step towards understanding the factors that impact preference for use. The following section provides context for this research by examining key literature on education and gamification as well as technology acceptance models used as inspiration for the research.

\section{Background}

The purpose of this research is to understand the factors that contribute to students engaging with a learning activity using gamification. The following sections explore how gamification and education can be combined as well as models that currently exist to measure technology 
acceptance. Combined, these sections will provide guidance for the development of a factor model of educational gamification in this research.

\subsection{Gamification and Education}

Gamification refers to the use of game mechanics, aesthetics and thinking in non-game contexts to engage users and solve problems (Deterding et al., 2011; Kapp, 2012; Zichermann \& Cunningham, 2011). Although gamification uses game elements, the resulting application is not akin to a commercial game. The term is also confused as the application of entertainment or serious games, which is incorrect, as gamification is the process to create something that is game-like, but not an actual video game (Werbach, 2014). It could be argued that education is already game-like in that students are given tasks to complete (assignments), receive points for completing them (assignment being marked), which are converted to badges (grades) that they can use to "level up" (graduate to the next year level) (Lee \& Hammer, 2011). This implies that gamification may be well suited for the learning environment. However, for gamification to be used in a meaningful way in the classroom it must also make a connection to the underlying non-game elements of the class activities (Nicholson, 2012), which are the learning objectives. One cannot simply add game elements such as badges, points and rewards to any aspect of a class activity and expect engagement and learning to be improved (Kapp, 2012).

One advantage of using gamification is being able to tailor implementations to specific needs, due to the modular nature of game elements. When implemented correctly and appropriately within the learning environment, gamification can enable a number of benefits. For instance, the stress of failure within the learning process can be eased as students can deal with the feedback of failure in a positive manner by not worrying about the consequences (such as failing an assessment piece) (Simões, Redondo, \& Vilas, 2012). That is, as the consequence of a student failing a task is low, there is a likelihood that the student may attempt to solve the problem again (Gee, 2008), encouraging curiosity to learn.

\subsection{Measuring Technology Acceptance}

Numerous models such as Theory of Reasoned Action (TRA), Theory of Planned Behaviour (TPB), Innovation Diffusion Theory (IDT) and Social Cognitive Theory (SCT) have been developed to measure technology acceptance (Ajzen, 1991; Ajzen \& Fishbein, 1980; Bandura, 1986; Rodger, 1995). Unifying previous models of technology acceptance, the Unified Theory of Acceptance and Use of Technology (UTAUT) incorporates relevant aspects of each model and can be used to reliably measure user acceptance of an instance of technology. Its intention is to aid managers in understanding whether new technologies being introduced in the workplace would be successfully adopted (Venkatesh, Morris, Davis, \& Davis, 2003). The UTAUT model uses six key determinants for intention and usage of technology. These being: (1) Performance Expectancy, (2) Effort Expectancy, (3) Social Influence, (4) Facilitating Conditions, (5) Behavioural Intention and (6) Use Behaviour. The relationships between these are mediated by 4 other determinants: (1) Gender, (2) Age, (3) Experience and (4) Voluntariness of Use (Venkatesh et al., 2003). UTAUT is a capable framework however it is not suitable for this research. UTAUT does not feature any measurement items for fun and enjoyment, which is a crucial aspect to measuring the success of an implementation using gamification. Some of the determinants and mediators will be adapted for use in the model created for this research, however the model as originally defined will not be used. 


\subsection{Related Work}

The purpose of gamification is to replicate the type of engagement and motivation people traditionally experience with video games in learning contexts. One study, conducted by Bourgonjon, Valcke, Soetaert, and Schellens (2010), attempted to model student acceptance of video games in a classroom setting. This was achieved by measuring the students' preference for video games, from which acceptance could be derived. The study identified various factors that influence preference for video games. These included: usefulness, learning opportunities, ease of use, gender and experience. A limitation of this study was that respondents were not actually asked to use a particular video game in class. This research addresses this limitation by providing students with a game-like learning activity and then surveying them on the experience using the gamified learning tool. The tool selected does not need to be technically advanced as low complexity games are capable of still being interesting to students (Fu, Su, \& $\mathrm{Yu}, 2009)$.

\section{Conceptual Model}

In this research, a model is developed to measure students' preference for use of a gamified learning activity, identifying factors that influence students' views on this approach. At a highlevel, the conceptual model combines two distinct concepts of fun and learning. The constructs included in fun are: Enjoyment, Ease of Use, Immersion, Engagement, Game Experience and Social Interaction. As part of learning, constructs include: Knowledge Improvement and Usefulness. The following sub-sections explore these constructs further and the relationships they have between one another, culminating in the construction of the conceptual model.

\subsection{Usefulness and Preference for Use (USE and PRF)}

The foundation of the model being tested in this research is the relationship between Usefulness and Preference for Use. Students desire their learning experiences to occur in a way that is relevant and useful to them (Prensky, 2010) and so if they find a particular learning tool useful, they are more likely to have a preference for using it. The learning tool in this research is the gamified activity, which supports students to improve in tangible ways such as in learning performance, productivity, and grades. Any implementation of gamification needs to ensure that it supports these aspects of student learning. As such, the first hypothesis is:

H1. Usefulness of a gamified activity positively affects preference for use.

\subsection{Knowledge Improvement (KNO)}

If a class activity that has been gamified is perceived by students to improve their knowledge, then this will contribute to whether they find the activity useful overall. One may argue that knowledge improvement and usefulness are one and the same as the primary purpose of education is to gain knowledge, hence, a learning tool can only be useful if it enables knowledge improvement. However, knowledge improvement and usefulness in this research measure different aspects. Usefulness measures the learning tool itself while knowledge improvement measures student perception of whether their knowledge has improved or not when using the gamified tool. For example, students may believe that a gamified learning tool assists with the process of studying by considering it a vehicle for learning. However, they may not attribute any knowledge improvement from the use of the tool even if that is what occurred. Lack of attribution in this scenario may be due to self-serving bias, where people are more likely to attribute successes to themselves (Miller \& Ross, 1975). If students do believe 
they have improved their knowledge from using the tool, they are likely to also think that the tool is useful as it helped them to achieve their learning goal. Hence, the impact of knowledge improvement can be viewed as a determinant of usefulness. This concept can be hypothesised as:

H2. Knowledge improvement positively affects usefulness of a gamified activity.

\subsection{Engagement (ENG) and Immersion (IMM)}

The terms engagement and immersion are often used synonymously, however, there is a difference between the two. When considered from the perspective of video game design, one can define three types of interactivity: immersion, engagement and presence (McMahan, 2003). Immersion occurs when players are caught up in a game's story or are deeply involved in the strategy of playing the game. Engagement occurs when players derive enjoyment from interacting with the game mechanics. Presence involves feeling part of a game's world and is typically used to describe Virtual Reality experiences. As such, presence will be excluded from this research as it is out of scope. Linking the definitions of interactivity to a gamified learning context, immersion can involve students thinking deeply about how best to use the learning tool at a strategic level. Engagement can involve students making a connection to the game mechanics and enjoying the experience of playing. This aligns well with the definition of student engagement provided earlier: engaged students pay attention, are interested in the material and are curious to learn more. Arguably, the areas of attention, interest, and curiosity are the mechanics of learning, much like points, badges and leader boards are mechanics of games. This is important because students who are engaged in their studies devote more time to developing their skills which will be useful to them later in life (Kuh, 2003), and this one of the goals of formal education.

To promote immersion, the system should attempt to induce students into a state where they devote their entire attention to it in a way that brings them immense satisfaction. This experience is called "flow" (Csikszentmihalyi, 1990). When in a state of flow there is a greater chance that learning can occur (Muntean, 2011). In other words, when students are in a state of flow with a class activity, they are completely immersed in it. Being in a state of flow is characterised by the following conditions: (1) the likelihood of completing the task must be relatively good, (2) the goals are clear and immediate feedback is provided, and (3) complete concentration can be given to the task. If a gamified learning task creates these conditions, it is reasonable to expect that the student finds the tool to be useful, as it enabled them to become completely absorbed in something enjoyable.

In summary, being engaged in the mechanics of a gamified tool and immersing students in the strategy of playing means that engagement and immersion as separate constructs are determinants of whether students will find the tool to be useful. These can be hypothesised as:

H3. Engagement in a gamified activity positively affects its usefulness.

H4. Immersion in a gamified activity positively affects its usefulness.

\subsection{Enjoyment (ENJ)}

Enjoyment of a class activity is important for learning to take place (Frenzel, Goetz, Lüdtke, Pekrun, \& Sutton, 2009). If students are having fun completing an activity, then they are more likely to be relaxed, leading to increased ability to learn (Prensky, 2001). The concept of 
enjoyment for a gamified learning activity stems from why people play games, and that is for the fun of play. It is sometimes difficult to replicate fun and play in learning environments as formal assessment is required to measure academic progress, and students can develop feelings of stress and anxiety when they are being tested (Cassady \& Johnson, 2002). Therefore, fun and enjoyment should be prioritised when formal assessment is not being conducted. For example, instructors may use pop culture references to make educational material more contextual so students find it more enjoyable to discuss (Cheung, 2001). It is likely that enjoyment would only impact preference for use and not usefulness, as students may not enjoy using a tool but they may see its value in helping them to learn. However, if the tool is not enjoyable, even if it is useful, student preference for use would likely be impacted. This leads to the hypothesis:

H5. Enjoyment of a gamified activity positively affects preference for its use.

\subsection{Experience (EXP)}

In a game-like environment, the relationship between enjoyment and preference for use is expected to be moderated by video game experience. This research will be using digital gamification that makes an experience more 'game-like', so it is reasonable to presume that students' prior history of playing video games would impact their proclivity for such an experience. The impact of video game experience can be two-fold. Firstly, students who play video games often may be more likely to enjoy using an educational class activity that is gamified as it more closely resembles what they enjoy doing in their leisure time. Conversely, students who play video games regularly may find the game elements featured in class to be lacklustre and as such may negatively impact their feelings of enjoyment related to preference for use. Students who do not play video games at all may not find the activity enjoyable due to unfamiliarity. For these reasons, video game experience is considered a moderating factor and can be hypothesised as:

H6. Video game experience moderates the impact enjoyment has on preference for use.

\subsection{Social Interaction (SI)}

One way to help improve student academic engagement is to also support student social engagement (Coates, 2007). Students are likely to expect some type of social element built into a system that is game-like, particularly given the popularity of text and voice chat in online games. However, social interaction can also be achieved by interacting in the physical world, similar to traditional split-screen multiplayer games where players interacted by sitting together on the same couch. Being physically next to others would likely spur interaction and would create a moderating effect on the impact engagement, immersion and enjoyment have on usefulness and preference for use. Therefore, the moderating effect of social interaction can be hypothesised in the following ways:

H7. Social interaction moderates the impact enjoyment has on preference for use.

H8. Social interaction moderates the impact immersion has on usefulness.

H9. Social interaction moderates the impact engagement has on usefulness. 


\subsection{Ease of Use (EoU)}

Ease of use plays a large role in moderating the relationships between the determinant factors in the model. If something is easy to use then this allows one to concentrate on using the system for its intended purpose, rather than focus their attention on how to operate it (Krug, 2014). A learning tool that is difficult to use would distract students from their main task of learning course material, leading to a possible reduction in a student's perceptions of knowledge improvement, engagement, immersion and enjoyment. For this reason, the impact of ease of use can be hypothesised in the following ways:

H10. Ease of use moderates the impact enjoyment has on preference for use.

H11. Ease of use moderates the impact immersion has on usefulness.

H12. Ease of use moderates the impact engagement has on usefulness.

H13. Ease of use moderates the impact knowledge improvement has on usefulness.

\subsection{Overall Model}

In summary, having outlined the hypotheses, a model can be illustrated to represent all of the variables and their moderators, as can be seen in Figure 1.

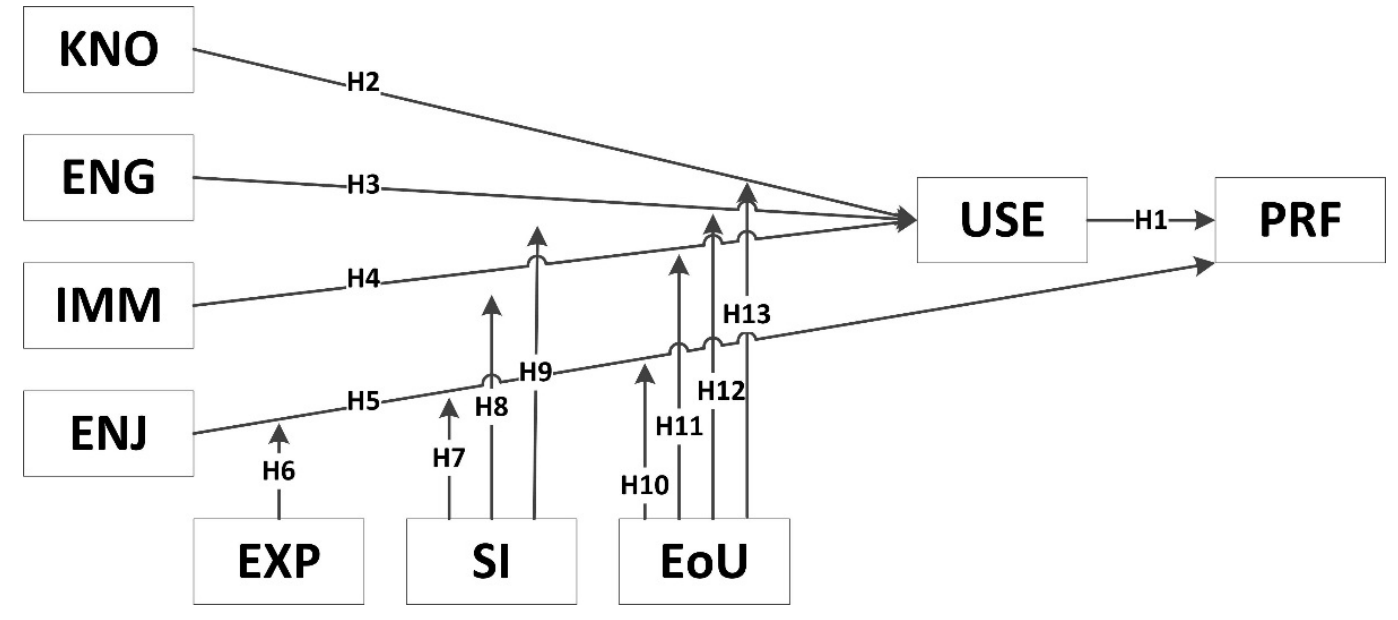

Figure 1: Conceptual Acceptance Model

\section{Methodology}

As part of regular class activities, several courses from a Business Information Systems degree used a gamified multiple-choice quiz called Quick Quiz (Cheong, Cheong, \& Filippou, 2013). In total, three courses were selected. Each of these courses is primarily IT-based in terms of the content taught. All three courses feature a weekly one-hour lecture as well as a two-hour tutorial. Quick Quiz was used by students on laptops during tutorials for a period of three to four weeks. The instructors for each course developed their own course-related questions and were not given any strict instructions on how to integrate the tool into the tutorial. The instruction was simply to do so in a manner that suited the class.

\subsection{Quick Quiz}

Quick Quiz is designed to be a fun and flexible way for instructors to test students on their knowledge of a given class topic. The general gameplay involves short, timed quizzes that contain a number of questions in multiple-choice format. Each quiz features 5 questions with each given 60 seconds as a time limit for students to answer. Students join a quiz when the 
instructor has activated it and immediately begin answering questions. Quick Quiz utilises the multiple-choice question format as it is commonly used and therefore the tool can be tailored for use in many different subject areas. This format also allows students to quickly submit responses as compared to requiring open response questions.

A number of game elements are evident in Quick Quiz. For instance, Quick Quiz features a point system, where the quicker students answer a question, the more points they receive (within the range of 50 to 100 points). If students answer questions incorrectly, they are awarded a participation score of 20 points. No points are awarded to the student if no response is given to a question. Immediate visual feedback is also conveyed to the student using progress bars indicating time remaining, as well as ticks and crosses immediately informing students on the result of their selected answer (see Figure 2). At the conclusion of a game, a leader board is displayed that ranks all of the students based on the points they were awarded (see Figure 3 - student names have been anonymised).

\begin{tabular}{|l|}
\hline \multicolumn{1}{|c|}{ Maths Knowledge 01} \\
\hline $\begin{array}{l}\text { In the following equation, the number } 8 \text { is known as the what? } \\
8 / 4=2\end{array}$ \\
\hline Select an Answer: \\
\hline $\mathbf{X}$ Division \\
\hline $\mathbf{C}$ Dividend \\
\hline Divisor \\
\hline Divider \\
\hline
\end{tabular}

Figure 2: Student has selected an incorrect answer

\begin{tabular}{|c|c|c|}
\hline \multicolumn{3}{|c|}{ Leaderboard for Session } \\
\hline \multicolumn{3}{|c|}{ Leaderboard } \\
\hline Rank & Player & Score \\
\hline 1 & Scott Summers & 338 \\
\hline 2 & Jean Grey & 336 \\
\hline 3 & Steve Rogers & 336 \\
\hline 4 & Charles Xavier & 260 \\
\hline 5 & Tony Stark & 180 \\
\hline 6 & Bruce Wayne & 180 \\
\hline 7 & James Howlett & 179 \\
\hline 8 & Clark Kent & 178 \\
\hline 9 & Peter Parker & 100 \\
\hline 10 & Bruce Banner & 100 \\
\hline
\end{tabular}

Figure 3: Personalised leader board shown at the completion of a quiz

A number of features are available to instructors to address the learning component of playing the quiz. Once students have completed the quiz, instructors have a number of charts at their disposal containing class performance data. A histogram is available that graphs all answers submitted by students for each question. This is a particularly useful tool as it becomes clear which questions students understood and those there was difficulty in answering. This allows feedback to be provided to students to aid them in their learning, and also allows instructors 
to identify common misconceptions among students, by highlighting questions where student responses were diverse.

Quick Quiz was purpose-built to be a fun exercise for students while being useful for learning. With several game elements including points scoring, timers, progress bars and leader boards, combined with the game thinking of having instructors provide immediate feedback on the class' performance in the quiz, Quick Quiz is suitably gamified to use as a base to measure preference for use of gamification in education.

\subsection{Instrument Development}

A paper-based survey was used in this research paper based surveys are more likely to have higher response rates (Hayslett \& Wildemuth, 2004). Given that there are only three courses available as targets for this study, maximising the possibility of survey response is imperative. The questionnaire features two parts. Part A enquires about the general demographic details of the participant. Part B of the questionnaire contains items that directly measure the conceptual model constructs, which are adapted from previous research studies and are known to be reliable (see Appendix A for the list of questions). Although the original questionnaire items being sourced were not used for gamification, they are general enough that adaptation can be reasonably executed. Respondents were asked to rate how much they either agreed or disagreed with each statement using a 5-point Likert scale. The scale was structured as: (1) strongly disagree, (2) disagree, (3) neither agree nor disagree, (4) agree, (5) strongly agree. Students were also provided with a Participant Information and Consent Form stating that completion of the survey is voluntary and that no student is identifiable.

\subsubsection{Pilot and Instrument Refinement}

To verify the survey instrument, a pilot study was performed at the end of the semester with students in the target courses. The purpose of this was to ensure that the questions being asked were being interpreted by respondents correctly and as such, would provide appropriate data. This was achieved by having students play Quick Quiz and answer questions on the questionnaire. Responses were analysed by observing the responses given in the survey and identifying any patterns that were unexpected. In total, there were 11 participants, including:

- 10 males and 1 female

- $\quad 7$ aged 18-21 and 4 were aged 22-28

- 6 local and 5 international students

- $\quad 9$ full-time and 2 part-time students

Upon analysing the responses to the questions only a small number of issues were identified. Respondents were asked to provide the course they were undertaking. Many respondents confused this with the program title and not the course title. To rectify this, check boxes were used and only provided options for the target courses. Part B of the questionnaire contained question numbering issues however this did not impact the respondents' ability to answer the questions. The data collected as part of the pilot was not used in the main data collection.

\subsection{Statistical Design}

The conceptual model includes a number of relationships between various factors based on hypotheses presented earlier. As such, Structural Equation Modelling (SEM) was used to perform a Confirmatory Factor Analysis (CFA) as it is suited to this type of the empirical data 
(Haenlein \& Kaplan, 2004). More specifically, the Partial Least Squares (PLS) regression technique was used. The factors in the model are latent variables, with an inner and outer structural model, which is a type suited to PLS (Hair, Black, \& Babin, 2010) Linear regression and Multiple-Linear regression cannot be used as the relationships cannot be isolated to measure the individual effects. SmartPLS software was used to derive the models (Ringle, Wende, \& Will, 2005). The reliability of the model was determined by the Cronbach's alpha values for each of the latent variables, which indicates internal consistency of the measurement items in a range between 0 and 1 (Santos, 1999). A value closer to 1 suggests greater reliability of the instrument. Values of 0.7 or greater are considered optimal; however values between 0.5 and 0.7 are acceptable. Any value below 0.35 is rejected (Hair et al., 2010). Finally, the data was cleaned using a four-step process: (1) identification if missing data is non-random and therefore ignorable, (2) determining impact of missing data to final results, (3) determining how random the missing data is and (4) applying a remedy (Hair et al., 2010). Missing data was handled by using the 'Complete Case Approach' imputation method that involves only using complete and valid observations.

\section{Results}

The survey was distributed to a total of 119 enrolled students with 84 students completing and returning their survey. This represented an initial response rate of $70.59 \%$ from the available students. However, not all surveys returned were usable with 8 surveys being excluded from the usable data set as they were missing a significant number of answers and a complete case approach was being used. Following the data cleaning there were a total of 76 usable observations, representing $63.86 \%$ of students from the population of classes sampled.

\subsection{Descriptive Statistics}

The data collected is representative of the overall population of students in the target classes as most characteristics from the sample fall within one per cent of the population percentage. Gaming demographic details are unavailable for the population and so a comparison is not possible. Table 1 provides an overview of the demographic details.

\begin{tabular}{|c|c|c|c|c|}
\hline \multirow[t]{2}{*}{ Characteristics } & \multicolumn{2}{|c|}{ Population } & \multicolumn{2}{|c|}{ Sample } \\
\hline & Count & $\%$ & Count & $\%$ \\
\hline \multicolumn{5}{|l|}{ Gender } \\
\hline Male & 97 & $81.51 \%$ & 62 & $81.58 \%$ \\
\hline Female & 22 & $18.49 \%$ & 14 & $18.42 \%$ \\
\hline \multicolumn{5}{|l|}{ Age Group } \\
\hline $18-21$ & 81 & $68.07 \%$ & 55 & $72.37 \%$ \\
\hline $22-28$ & 33 & $27.73 \%$ & 20 & $26.31 \%$ \\
\hline $29-48$ & 5 & $4.20 \%$ & 1 & $1.32 \%$ \\
\hline $49-65$ & 0 & $0 \%$ & 0 & $0 \%$ \\
\hline$>65$ & 0 & $0 \%$ & 0 & $0 \%$ \\
\hline \multicolumn{5}{|l|}{ Mode of Study } \\
\hline Full time & 113 & $94.96 \%$ & 71 & $93.42 \%$ \\
\hline Part time & 6 & $5.04 \%$ & 5 & $6.58 \%$ \\
\hline \multicolumn{5}{|l|}{ Student Type } \\
\hline Local & 96 & $80.67 \%$ & 61 & $80.26 \%$ \\
\hline International & 23 & $19.33 \%$ & 15 & $19.74 \%$ \\
\hline
\end{tabular}

Table 1: Descriptive Statistics 
Results from Part A of the survey (demographic) revealed that the students typically play computer games on a very frequent basis with a total of $65.8 \%$ playing computer games either daily or weekly. The three most common reasons they play games were: 'to play with others', 'boredom' and 'mental challenge'. Mental challenge being a typical reason to play games is encouraging as it suggests that gamification may likely have higher preference for use as it can be used to promote the mental challenges presented to students through their class activities in a game-like manner. 59.3\% of respondents had previously played educational games in class. Although the survey did not enquire about whether students found those experiences to be positive or negative, it did ask about students' interest in potentially learning with a game for future use. $63.2 \%$ of respondents were interested in learning with a game, so regardless of previous gaming experience, students generally are quite positive about the idea. This could mean that these students would be more likely to have a preference for use of a gamified system, given that they are generally interested in the idea of gaming.

Overall, it appears that the sample collected was representative of the population, and that this particular sample of students reports regularly playing video games which is important to provide context for analysing the results of the SEM-PLS analysis.

\subsection{Structural Equation Modelling Results}

In the initial model output it was evident that a number of issues were present. Firstly, CFA analysis identified a number of factor loadings for each of the measurement items as being quite low. A value greater than 0.7 is considered a reliable measure of that item, and any value less than 0.5 should be considered for removal (Hair et al., 2010). Some measurement items had values less than 0.5 and many of the moderators also exhibited low factor loadings. The results also indicated several instances of multicollinearity. Analysing the t-statistics of the model uncovered a number of paths that did not have statistical significance, which needed to be addressed. It was evident that the conceptual model needed revision. Several factors were however found to be reliable and so it was decided to restructure the model based on these, as well as re-consulting the literature. It is generally recommended that the number of samples should be proportional to the number of measurement items by a factor of 10 (Flynn \& Pearcy, 2001). 76 samples were collected for this study, and based on the ratio just mentioned, the study would require at least 480 observations ( 48 items $\times 10$ ). Therefore, the revised model takes the smaller sample size into consideration by including fewer factors and measurement items.

\subsection{Revised Conceptual Model}

The model was revised over several iterations to ensure it accurately measured the necessary factors while improving the statistical significance of the overall model. This was achieved by reconsidering each factor and measurement item against how it applied to the use of Quick Quiz. The original model was designed to cover gamification implementations generally and so some factors may not be relevant to the particular implementation used as in this study. Measurement items were also reviewed and items that did not match with the use of Quick Quiz were removed. Some items were deemed to be unnecessary as Quick Quiz did not directly implement certain game features and hence these aspects could not be measured. By carrying out this process, it was expected that a more relevant and simpler model would lead to improved results. 
Factors that were removed from the model included: 'gaming experience', 'social interaction', 'ease of use', 'gender', 'age' as well as all of the moderators. This was firstly due to the low path coefficients these factors produced in the initial tests, and also as a result of the sample demographic data being homogenous. The sample contained respondents who played games regularly, were predominately male, and typically were within the range of 18-21 years old. Therefore, video game experience and ease of use were presumed to not have a large impact on respondents and added unnecessary complexity to the model. This was also applicable to gender and age for the same reasons. Social interaction was removed as Quick Quiz does not feature any component that enables this within the tool. Although the original hypothesis discussion earlier listed physical proximity as a means for conducing social interaction, observations of the instructors indicated that this did not occur to significant levels during the game. Several individual measurement items of the remaining factors were also removed to limit the total number of items further. The final conceptual model that was derived from this process can be found in Figure 4.

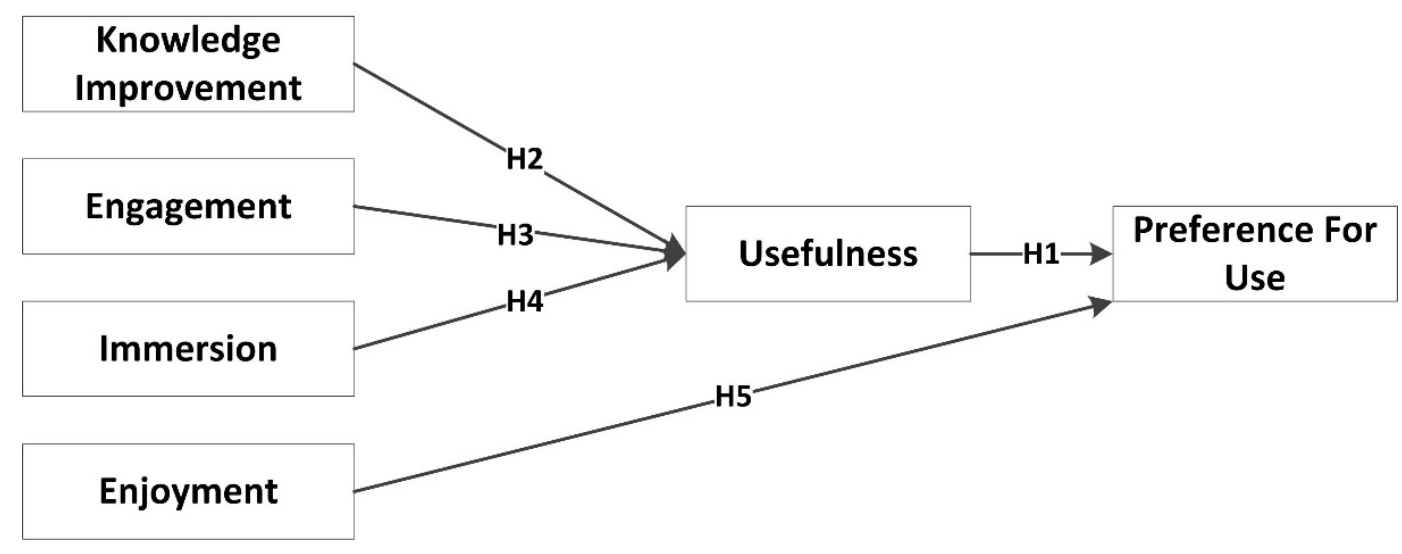

Figure 4: Revised Conceptual Model

Using the revised conceptual model, both the PLS algorithm and the bootstrapping algorithm were run once more. The output of the PLS algorithm can be found in Figure 5 while the bootstrapping algorithm output can be found in Figure 6. It can be observed from these outputs that a much-improved model was the result. All but 2 measurement items have a factor loading of 0.7 or greater, indicating very reliable measures of the factors. The remaining 2 items are both greater than 0.5 and while not as strong, can still be considered adequate. Excluding enjoyment, each of the path coefficients had values greater than 0.2 indicating each had a direct positive impact on either usefulness or preference for use. Enjoyment failed to produce a significant value, however its role in determining preference for use was considered vital and was retained. The amount of variance explained for usefulness dropped in this model, although remained at a significant value of $64.3 \%$. Variance in preference for use improved marginally to $48.9 \%$ variance explained. 


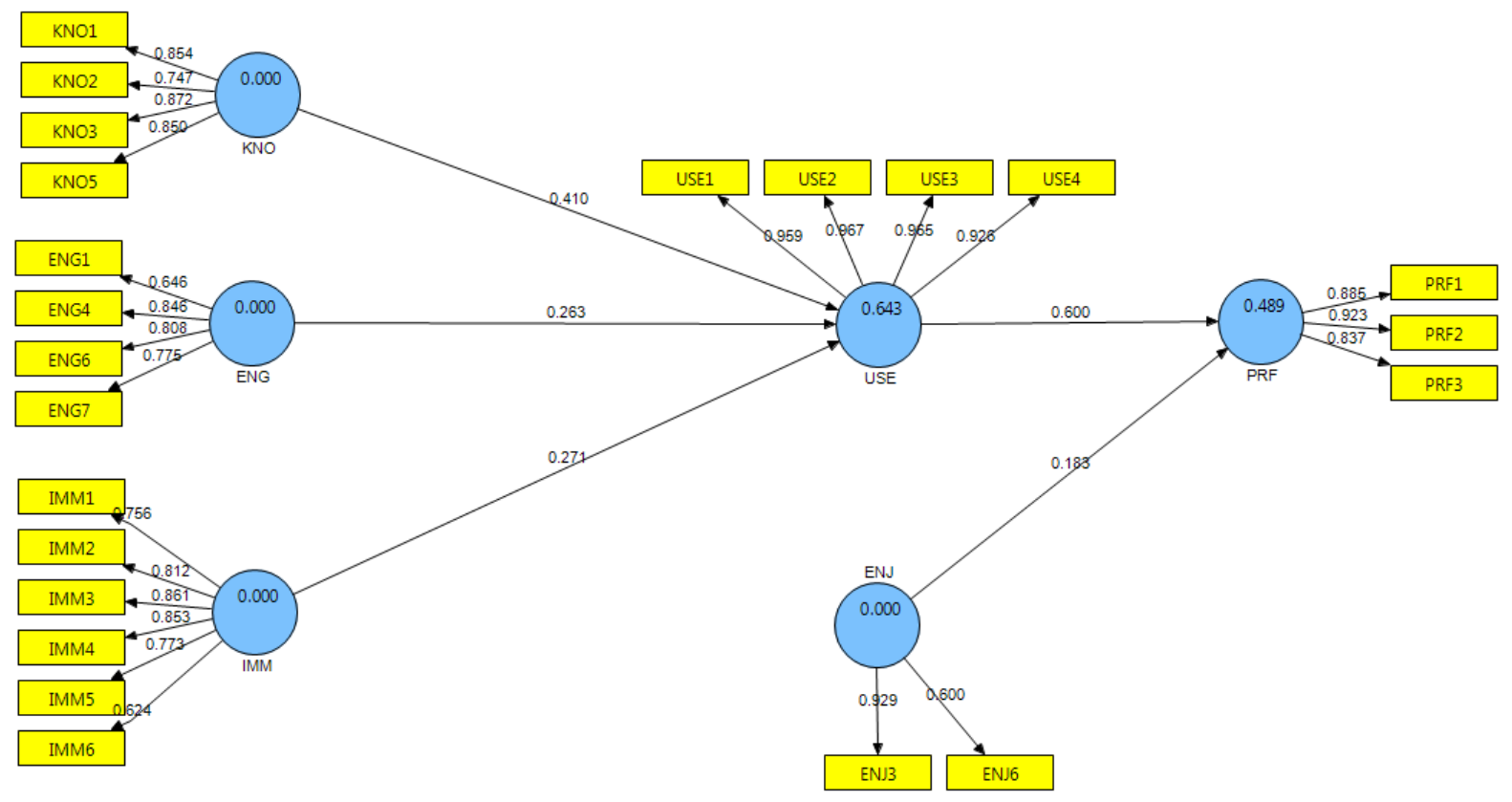

Figure 5: Path Coefficients

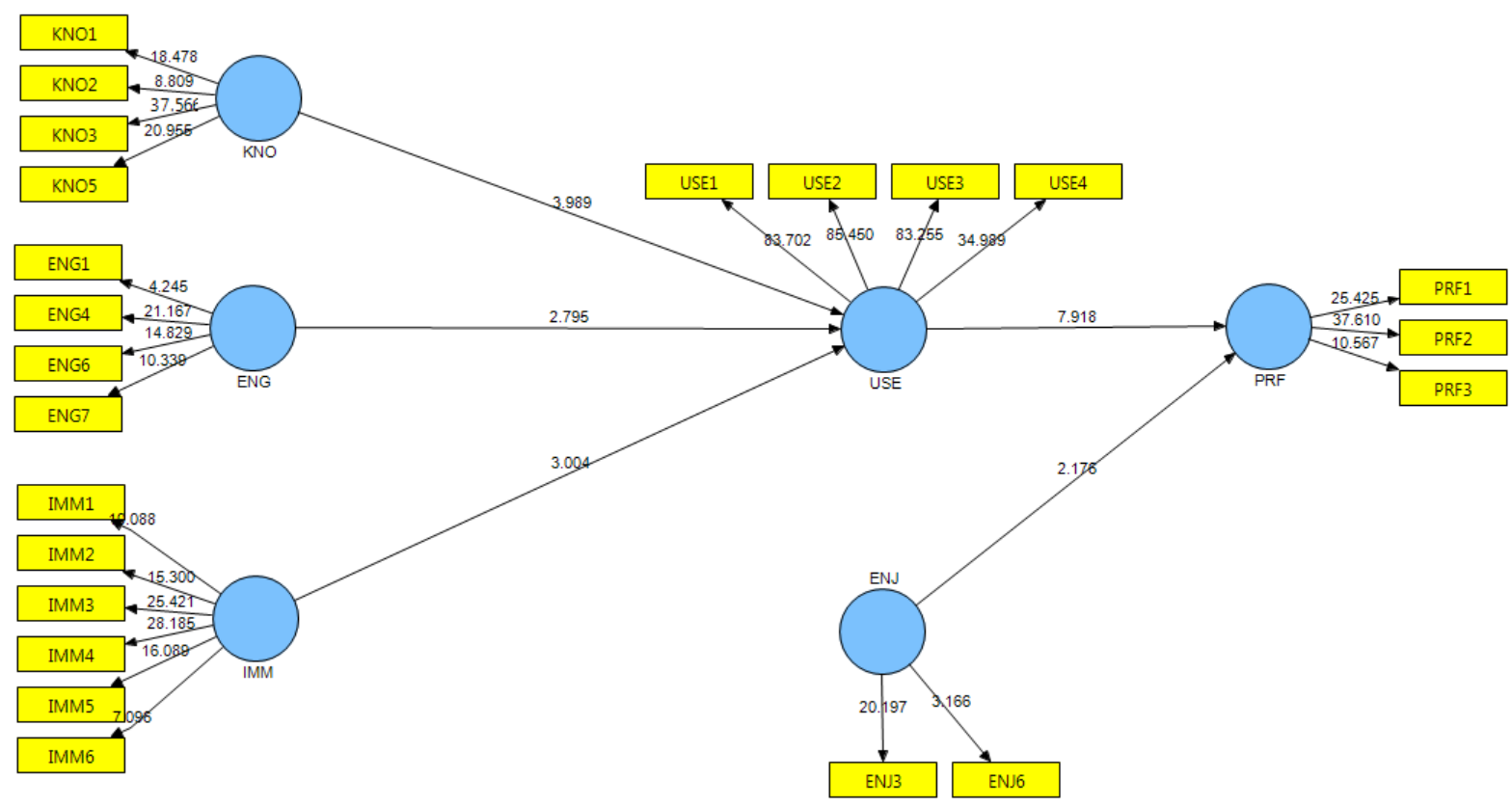

Figure 6: -statistics

\subsection{Revised Conceptual Model Reliability and Validity}

An issue with the original model tested was the amount of multicollinearity among the measurement items. As can be deduced from Table 2, almost all of the measurement items only show strong factor loadings for the factors they represented. The only exception to this is USE1 and USE2 which also had significant loadings for KNO. However, the loadings these items represented for usefulness were very strong with loadings of 0.95 and 0.96 respectively, whereas loadings for KNO were 0.70 for each, marginally over the cut-off. Therefore, these values were considered acceptable for this study. 


\begin{tabular}{|lllllll|}
\hline & \multicolumn{1}{c}{ ENG } & ENJ & \multicolumn{1}{c}{ IMM } & \multicolumn{1}{c}{ KNO } & \multicolumn{1}{c}{ PRF } & \multicolumn{1}{c}{ USE } \\
ENG1 & 0.646 & 0.4559 & 0.2647 & 0.4722 & 0.5334 & 0.3622 \\
ENG4 & 0.8455 & 0.3784 & 0.3917 & 0.5138 & 0.6117 & 0.5977 \\
ENG6 & 0.8081 & 0.3925 & 0.675 & 0.578 & 0.5091 & 0.6004 \\
ENG7 & 0.7746 & 0.4602 & 0.4813 & 0.3727 & 0.4254 & 0.508 \\
ENJ3 & 0.5385 & 0.9289 & 0.4473 & 0.3922 & 0.4405 & 0.3735 \\
ENJ6 & 0.2234 & 0.6 & 0.249 & 0.211 & 0.2039 & 0.3229 \\
IMM1 & 0.4434 & 0.3052 & 0.7557 & 0.3679 & 0.3351 & 0.4714 \\
IMM2 & 0.3946 & 0.308 & 0.8122 & 0.2495 & 0.2994 & 0.4199 \\
IMM3 & 0.4712 & 0.4721 & 0.8611 & 0.3748 & 0.373 & 0.5003 \\
IMM4 & 0.4994 & 0.3839 & 0.853 & 0.4144 & 0.3401 & 0.5546 \\
IMM5 & 0.5986 & 0.3452 & 0.7728 & 0.5622 & 0.5174 & 0.5977 \\
IMM6 & 0.3885 & 0.3783 & 0.6242 & 0.2962 & 0.346 & 0.3803 \\
KNO1 & 0.5189 & 0.4881 & 0.3571 & 0.854 & 0.6787 & 0.5653 \\
KNO2 & 0.507 & 0.3859 & 0.3154 & 0.7467 & 0.4292 & 0.4479 \\
KNO3 & 0.4967 & 0.2729 & 0.4416 & 0.8719 & 0.5905 & 0.6979 \\
KNO5 & 0.577 & 0.2464 & 0.5174 & 0.85 & 0.5785 & 0.6109 \\
PRF1 & 0.5463 & 0.469 & 0.4176 & 0.6213 & 0.8855 & 0.5867 \\
PRF2 & 0.6541 & 0.4181 & 0.4031 & 0.6938 & 0.9226 & 0.6447 \\
PRF3 & 0.5648 & 0.274 & 0.4519 & 0.4969 & 0.8374 & 0.564 \\
USE1 & 0.6897 & 0.4089 & 0.6106 & 0.7021 & 0.6434 & 0.9592 \\
USE2 & 0.6685 & 0.4165 & 0.6032 & 0.7029 & 0.6614 & 0.9666 \\
USE3 & 0.6439 & 0.4361 & 0.6372 & 0.6823 & 0.6134 & 0.9654 \\
USE4 & 0.6079 & 0.3932 & 0.569 & 0.6203 & 0.6754 & 0.9262 \\
\hline
\end{tabular}

Table 2: Final Model Cross Loading (Full Data)

The values of each factor's Cronbach's alpha can be found in Table 3 and are all very strong for each factor, excluding ENJ which has a weaker value. Although the Cronbach's alpha value for ENJ was weaker, it was still over the cut-off of 0.35 and so can remain in the final model. In addition to analysing the Cronbach's alpha value, the convergent validity and discriminant validity were also examined. Convergent validity refers to the amount of variance the items of a construct share. An Average Variance Extracted (AVE) of at least 0.5 and greater is adequate for convergent validity to exist (Fornell \& Larcker, 1981). Table 3 outlines the AVE for each factor in the model. Each factor has an AVE greater than 0.5 which confirmed discriminant validity.

\begin{tabular}{|lrlllll|}
\hline & AVE & $\begin{array}{l}\text { Composite } \\
\text { Reliability }\end{array}$ & $\mathbf{R}^{\mathbf{2}}$ & $\begin{array}{l}\text { Cronbachs } \\
\text { Alpha }\end{array}$ & Communality & $\begin{array}{l}\text { Redunda } \\
\text { ncy }\end{array}$ \\
ENG & 0.5963 & 0.8541 & 0 & 0.7733 & 0.5963 & 0 \\
ENJ & 0.6114 & 0.7505 & 0 & 0.4141 & 0.6114 & 0 \\
IMM & 0.6144 & 0.9044 & 0 & 0.8723 & 0.6144 & 0 \\
KNO & 0.6924 & 0.8997 & 0 & 0.8524 & 0.6924 & 0 \\
PRF & 0.7788 & 0.9134 & 0.4887 & 0.8575 & 0.7788 & 0.0998 \\
USE & 0.9111 & 0.9762 & 0.6426 & 0.9674 & 0.9111 & 0.2648 \\
\hline
\end{tabular}

Table 3: Reliability Measurements 
The amount in which a construct is truly distinct from other constructs is known as discriminant validity. The square root of the AVE for each construct should be greater than the other factor correlations for discriminant validity to be present (Chin, 1998). Table 4 outlines the correlations of the latent variables; from which, it can be deduced that the square root of the AVE is greater than correlations between the other factors.

\begin{tabular}{|lllllll|}
\hline & \multicolumn{1}{c}{ ENG } & \multicolumn{1}{c}{ ENJ } & \multicolumn{1}{c}{ IMM } & KNO & PRF & USE \\
ENG & 1 & & & & & \\
ENJ & 0.532 & 1 & & & & \\
IMM & 0.6055 & 0.4662 & 1 & & & \\
KNO & 0.627 & 0.406 & 0.4974 & 1 & & \\
PRF & 0.6679 & 0.4433 & 0.4781 & 0.6896 & 1 & \\
USE & 0.6841 & 0.4334 & 0.6339 & 0.7097 & 0.6793 & 1 \\
\hline
\end{tabular}

Table 4: Latent Variable Correlation

As a final step in presenting the results, the conceptual model hypotheses are evaluated. The null hypothesis is rejected if there was a path coefficient greater than $0.2, \mathrm{t}$-statistic greater than 2.0, and the Cronbach's alpha was 0.35 or greater. Hypotheses with values in unacceptable ranges result in the null hypothesis failing to be rejected. Table 5 outlines the results of each hypothesis tested.

\begin{tabular}{|lll|}
\hline H1 & $\begin{array}{l}\text { Hypothesis } \\
\text { Usefulness of a gamified activity positively affects preference for } \\
\text { use. }\end{array}$ & $\begin{array}{l}\text { Finding } \\
\text { Reject null hypothesis. }\end{array}$ \\
H2 & $\begin{array}{l}\text { Knowledge improvement positively affects usefulness of a } \\
\text { gamified activity. }\end{array}$ & Reject null hypothesis. \\
En3 & $\begin{array}{l}\text { Esefulness. } \\
\text { usent in a gamified activity positively affects its }\end{array}$ & Reject null hypothesis. \\
H4 & $\begin{array}{l}\text { Immersion in a gamified activity positively affects its usefulness. } \\
\text { Enjoyment of a gamified activity positively affects preference for } \\
\text { its use. }\end{array}$ & $\begin{array}{l}\text { Reject null hypothesis. } \\
\text { Reject null hypothesis. }\end{array}$ \\
\hline
\end{tabular}

Table 5: Summary of hypotheses

\section{Findings and Discussion}

This section provides a discussion of the results from two perspectives: (1) the reasons why some of the factors were retained and others were not, and (2) how the use of Quick Quiz may have influenced the results for this study.

\subsection{Factors}

The strong impact knowledge improvement had on usefulness confirms that students want their learning should be relevant (Prensky, 2001). The results showed that with every increase in the perception of knowledge improvement, usefulness rose by 0.41 . The indirect impact of knowledge improvement on preference for use can also be measured by multiplying the path coefficients. This leads to a coefficient of $0.25(0.41 \times 0.60)$, which is also notable. This significant relationship demonstrates that an important aspect to gamification design for learning tools is to prioritise student support for enhancing knowledge. 
Engagement and immersion were found to be significant factors, however the impact of each individually was not as strong as knowledge improvement. For every increase in engagement and immersion, there was an increase in usefulness of 0.26 and 0.27 respectively. However, as both factors are derived from interactivity in general, they can be added to better understand the effects on usefulness, resulting in a coefficient of $0.53(0.263+0.271)$. The combined effect immersion and engagement have on usefulness is greater than that of knowledge improvement. This suggests that students may have stronger preference for use if they feel engaged and immersed in a gamified system rather than if the learning tool simply provides them with knowledge. Although the factors can be combined, their implementation should be carried out as separate aspects. Engagement is created by giving students a reason to invest their time and effort in using a system they believe will be for their benefit. Alternatively, immersion is about absorbing students in the strategy of playing and ideally inducing a state of flow (Csikszentmihalyi, 1990) which alters students' perception of the environment around them while using the system. This allows deep concentration to occur, leading to a greater likelihood for learning to take place. Hence, it is unlikely a single feature will achieve both goals and is likely to require a combination of game features and the adjustment of the physical environment where the game is taking place.

The final factor of enjoyment had the weakest impact in the model. For every increase in enjoyment, preference for use only rose 0.183 . However, with every combined increase in usefulness and enjoyment, preference for use rose $0.783(0.600+0.183)$ which indicates a very strong relationship. This suggests that overall, two factors that are involved in students having a preference to use a gamified system is their perceived levels of enjoyment and usefulness, which reflects the aim of using gamification in education. That is, to make education fun and to better support the learning process. It is possible that students found playing a gamified quiz to be enjoyable due to the lack of consequences as a result of its use not being part of assessed coursework. This may have improved enjoyment, however it may have also weakened the value proposition of using Quick Quiz, in that there was no consequence to using it. Therefore, as happy as students were to play, they would not be unhappy if it was not used.

\subsection{Use of Quick Quiz}

It is also important to note that Quick Quiz did not contain a vast array of game-like features. Features such as points scoring, leader boards, and charts are some of the more prominent features used and yet several factors were identified as strong indicators of preference for use of a gamified learning tool. This may be a result of how Quick Quiz was used in class, rather than how its game-like features were implemented. At a point in time during the class (typically midway) instructors signalled to students that a round of Quick Quiz was to begin and so each student joined in the session online. As a first step, this has the effect of 'setting the scene' so that students switch their mindset from 'study' to 'gameplay' mode. When games commenced, instructors often provided running commentary as the leader board filled with students completing the quiz. At the conclusion of the round, instructors discussed the results with students in a conversational manner, allowing opportunity for students to explain why they selected their answers. When combined, the in-class experience presumably felt "gamelike" to students, hence why they were able to report on their preference for use. A finding that can be extrapolated from this scenario is that the importance of game mechanics in gamified learning tools are secondary to how the gamified experience is presented to students. 


\section{Implications for Research and Pedagogy}

A number of factors were validated in this research regarding student preference for use of a gamified learning activity. The factors highlight some important aspects for educators to consider when using gamified learning tools. It is evident that knowledge improvement is a significant determinant of preference for using a gamified system, so educators should place emphasis on this aspect as a priority when designing or selecting a gamified system. In Quick Quiz, knowledge improvement was achieved through instructors conducting class discussions and feedback at the conclusion of a round. This is an example of how educators play an important role in creating engagement in a gamified system by being a trigger. Instructors in this instance improved the experience of playing Quick Quiz by displaying a leader board to students and making encouraging comments throughout the game, thereby improving enjoyment of its use. The implication is that instructors and the physical learning environment play a significant role in ensuring a gamified learning tool is successful, and that software alone may not be as effective at creating an experience that is both fun and helps students learn simultaneously.

\section{Limitations}

There were a number of limitations in the research. Firstly, the research was exploratory in nature and so the results are not directly generalisable. Sample size availability also restricted the possible complexity of the conceptual model being tested. To validate a model of such complexity, the sample size is recommended to be proportional to the number of measurement items by a factor of 10 (Flynn \& Pearcy, 2001). Due to the limited number of courses Quick Quiz was used in, the population of potential respondents was less than the minimum suggested for statistical significance of the analysis. Hence, the entire original model was unable to be tested with an appropriate amount of data observations. Quick Quiz was used solely in IT-based undergraduate courses. Hence, the demographic of the collected sample was homogenous limiting the possibility of deeper analysis from taking place. Furthermore, Quick Quiz was trialled for only 3 to 4 weeks during a semester. This means that students were only exposed to the gamified quiz for a very limited timeframe, and so long-term perceptions of students using a gamified system could not be determined.

\subsection{Suggestions for Future Research}

Given the limitations of this study, there is room for future research to be conducted to further validate student preference for use of gamified learning tools. Firstly, the target population and sample size collected was relatively small, so re-conducting the study in a larger population of students may enable the more complex model to be further explored and examined. Students from different fields of study should also be surveyed. This will allow researchers to identify whether the factors identified in this study apply to a broad range of students, with differing skillsets and academic interests. The possibility of a unified set of factors or alternatively, different factors for specific demographics of students could potentially be developed as a result of this. Research can be conducted on comparing gamification preference for use between undergraduate and post-graduate students, evaluating whether enrolment in higher degrees moderate students willingness to engage in a learning activity that may be thought of as less serious.

Incorporating Quick Quiz into a teaching approach may be another avenue for further research. More broadly, investigating ways that gamified learning tools such as Quick Quiz 
could be formally incorporated into teaching approaches may be of interest to researchers. Although Quick Quiz was used as part of class activities, it was considered as a supplement to the established curriculum, rather than being an integral part of it. Students also selfreported that knowledge improvement occurred as part of using the gamified quiz, however a study investigating whether this actually occurs would likely have an impact on pedagogical research.

\section{Conclusion}

The results of this research indicate that students have a preference for use of a gamified educational tool. The model constructed identified factors that were found to be reliable contributors to student preference for use, including: 'usefulness', 'enjoyment', 'knowledge improvement', 'engagement' and 'immersion'. The factors of 'gaming experience', 'social interaction', 'ease of use', 'gender', 'age', were hypothesised but could not be reliably tested due to a restricted sample of data. It was found that a large set of game-like features was not required to determine preference for use. Rather, the experience of using a gamified learning tool in-class based on how instructors facilitate use is more important. Further work needs to be conducted to measure whether the results of this research are consistent across students of varying disciplines. The implications of measuring preference for use of gamification in education help to set a foundation for broader implementations of gamification in learning and teaching practice.

\section{Acknowledgements}

This research project was approved by the RMIT University Business College Human Ethics Advisory Network (BCHEAN project number 1000389).

The authors would like to thank the participants for their involvement in this study and the reviewers for providing insightful feedback.

\section{References}

Ajzen, I. (1991). The theory of planned behavior. Organizational behavior and human decision processes, 50(2), 179-211.

Ajzen, I., \& Fishbein, M. (1980). Understanding attitudes and predicting social behaviour.

Bandura, A. (1986). Social foundations of thought and action. Englewood Cliffs, NJ.

Bos, B., Wilder, L., Cook, M., \& O'Donnell, R. (2014). Learning mathematics through Minecraft. Teaching Children Mathematics, 21(1), 56-59.

Bourgonjon, J., Valcke, M., Soetaert, R., \& Schellens, T. (2010). Students' perceptions about the use of video games in the classroom. Computers \& Education, 54(4), 1145-1156.

Cassady, J. C., \& Johnson, R. E. (2002). Cognitive test anxiety and academic performance. Contemporary educational psychology, 27(2), 270-295.

Cheong, C., Cheong, F., \& Filippou, J. (2013). Quick Quiz: A Gamified Approach for Enhancing Learning. Paper presented at the Pacific Asia Conference on Information Systems, Jeju Island, Korea.

Cheung, C.-K. (2001). The use of popular culture as a stimulus to motivate secondary students' English learning in Hong Kong. ELT journal, 55(1), 55-61. 
Chin, W. W. (1998). Commentary: Issues and opinion on structural equation modeling. MIS quarterly, vii-xvi.

Coates, H. (2007). A model of online and general campus-based student engagement. Assessment \& Evaluation in Higher Education, 32(2), 121-141.

Connolly, T. M., Boyle, E. A., MacArthur, E., Hainey, T., \& Boyle, J. M. (2012). A systematic literature review of empirical evidence on computer games and serious games. Computers \& Education, 59(2), 661-686.

Csikszentmihalyi, M. (1990). The psychology of optimal experience. New York: Harper \& Row.

Deterding, S., Dixon, D., Khaled, R., \& Nacke, L. (2011). From game design elements to gamefulness: defining gamification. Paper presented at the Proceedings of the 15th International Academic MindTrek Conference: Envisioning Future Media Environments.

Djaouti, D., Alvarez, J., Jessel, J.-P., \& Rampnoux, O. (2011). Origins of serious games Serious games and edutainment applications (pp. 25-43): Springer.

Flynn, L. R., \& Pearcy, D. (2001). Four subtle sins in scale development: some suggestions for strengthening the current paradigm. International Journal of Market Research, 43(4), 409424.

Fornell, C., \& Larcker, D. F. (1981). Evaluating structural equation models with unobservable variables and measurement error. Journal of marketing research, 39-50.

Fredricks, J. A., Blumenfeld, P. C., \& Paris, A. H. (2004). School engagement: Potential of the concept, state of the evidence. Review of educational research, 74(1), 59-109.

Frenzel, A. C., Goetz, T., Lüdtke, O., Pekrun, R., \& Sutton, R. E. (2009). Emotional transmission in the classroom: Exploring the relationship between teacher and student enjoyment. Journal of Educational Psychology, 101(3), 705.

Fu, F.-L., Su, R.-C., \& Yu, S.-C. (2009). EGameFlow: A scale to measure learners' enjoyment of e-learning games. Computers E Education, 52(1), 101-112.

Gee, J. P. (2008). Learning and games. The ecology of games: Connecting youth, games, and learning, 3, 21-40.

Haenlein, M., \& Kaplan, A. M. (2004). A beginner's guide to partial least squares analysis. Understanding statistics, 3(4), 283-297.

Hair, J. F., Black, W. C., \& Babin, B. J. (2010). Multivariate Data Analysis: A Global Perspective: Pearson Education, Limited.

Hamari, J., Koivisto, J., \& Sarsa, H. (2014). Does gamification work?--a literature review of empirical studies on gamification. Paper presented at the System Sciences (HICSS), 2014 47th Hawaii International Conference on.

Hayslett, M. M., \& Wildemuth, B. M. (2004). Pixels or pencils? The relative effectiveness of Web-based versus paper surveys. Library E Information Science Research, 26(1), 73-93.

Kapp, K. M. (2012). The gamification of learning and instruction: game-based methods and strategies for training and education. San Francisco, CA: Wiley. 
Krug, S. (2014). Don't make me thing revisited: a common sense approach to web and mobile usability. USA: New Riders.

Kuh, G. D. (2003). What we're learning about student engagement from NSSE: Benchmarks for effective educational practices. Change: The Magazine of Higher Learning, 35(2), 24-32.

Kuh, G. D., Cruce, T. M., Shoup, R., Kinzie, J., \& Gonyea, R. M. (2008). Unmasking the effects of student engagement on first-year college grades and persistence. The Journal of Higher Education, 79(5), 540-563.

Lamborn, S., Newmann, F., \& Wehlage, G. (1992). The significance and sources of student engagement. Student engagement and achievement in American secondary schools, 11-39.

Lee, J. J., \& Hammer, J. (2011). Gamification in education: What, how, why bother? Academic Exchange Quarterly, 15(2), 146.

McMahan, A. (2003). Immersion, engagement and presence. The video game theory reader, 67, 86.

Miller, D. T., \& Ross, M. (1975). Self-serving biases in the attribution of causality: Fact or fiction. Psychological bulletin, 82(2), 213-225.

Muntean, C. I. (2011). Raising engagement in e-learning through gamification. Paper presented at the Proc. 6th International Conference on Virtual Learning ICVL.

Muratet, M., Torguet, P., Jessel, J.-P., \& Viallet, F. (2009). Towards a serious game to help students learn computer programming. International Journal of Computer Games Technology, 2009, 3.

Nicholson, S. (2012). A user-centered theoretical framework for meaningful gamification. Proceedings GLS, 8.

Prensky, M. (2001). Digital Game-Based Learning: McGraw-Hill.

Prensky, M. (2010). Teaching Digital Natives: Partnering for Real Learning: SAGE Publications.

QUT. (2014). Review of QUT's Virtual Learning Environment (VLE). Retrieved from http://www.els.qut.edu.au/innovation/vler/docs/VLEReview_Report_FIN_20140623.pd $\mathrm{f}$

Randel, J. M., Morris, B. A., Wetzel, C. D., \& Whitehill, B. V. (1992). The effectiveness of games for educational purposes: A review of recent research. Simulation \& Gaming, 23(3), 261276.

Ringle, C., Wende, S., \& Will, A. (2005). SmartPLS. Hamburg, Germany: University of Hamburg.

Risberg, C. (2015). More than just a video game: Tips for using Minecraft to personalize the curriculum and promote creativity, collaboration, and problem solving. Illinois Association for Gifted Children Journal, 44-48.

Rodger, E. (1995). Diffusion of innovations: New York: Free Press.

Santos, J. R. A. (1999). Cronbach's alpha: A tool for assessing the reliability of scales. Journal of extension, 37(2), 1-5. 
Simões, J., Redondo, R. D., \& Vilas, A. F. (2012). A social gamification framework for a K-6 learning platform. Computers in Human Behavior.

Venkatesh, V., Morris, M. G., Davis, G. B., \& Davis, F. D. (2003). User acceptance of information technology: Toward a unified view. MIS quarterly, 425-478.

Werbach, K. (2014). (Re) defining gamification: A process approach. Paper presented at the International conference on persuasive technology.

Zichermann, G., \& Cunningham, C. (2011). Gamification by Design: Implementing Game Mechanics in Web and Mobile Apps. Sebastopol, CA: O'Reilly Media. 


\section{Appendix A: Items Used To Measure Acceptance}

\begin{tabular}{|c|c|}
\hline Construct & Item \\
\hline \multirow{3}{*}{$\begin{array}{l}\text { Preference For Use } \\
\text { (Adapted from } \\
\text { Bourgonjon et al. } \\
\text { 2010) }\end{array}$} & $\begin{array}{l}\text { If I had the choice, I would choose to follow courses in which Quick Quiz } \\
\text { was used. }\end{array}$ \\
\hline & If I had to vote, I would vote in favour of using Quick Quiz in the classroom. \\
\hline & I am enthusiastic about using Quick Quiz in the classroom. \\
\hline \multirow{4}{*}{$\begin{array}{l}\text { Usefulness } \\
\text { (Adapted from } \\
\text { Bourgonjon et al. } \\
\text { 2010) } \\
\end{array}$} & Playing Quick Quiz improves my learning performance \\
\hline & Playing Quick Quiz increases my learning productivity \\
\hline & Playing Quick Quiz enhances my learning effectiveness \\
\hline & Playing Quick Quiz helps me to achieve better grades \\
\hline \multirow{5}{*}{$\begin{array}{l}\text { Knowledge } \\
\text { Improvement } \\
\text { (Adapted from Fu et } \\
\text { al. 2009) }\end{array}$} & The game increases my knowledge \\
\hline & I catch the basic ideas of the knowledge taught \\
\hline & I try to apply the knowledge in the game \\
\hline & The game motivates the player to integrate the knowledge taught \\
\hline & I want to know more about the knowledge taught \\
\hline \multirow{7}{*}{$\begin{array}{l}\text { Engagement } \\
\text { (Adapted from } \\
\text { Whitton 2007) }\end{array}$} & I wanted to complete the quiz. \\
\hline & I wanted to explore all of the options available to me. \\
\hline & I did not care how the quiz ended. \\
\hline & I found the quiz satisfying. \\
\hline & I felt absorbed in the quiz. \\
\hline & I felt that time passed quickly. \\
\hline & I felt excited during the quiz. \\
\hline \multirow{6}{*}{$\begin{array}{l}\text { Immersion } \\
\text { (Adapted from Fu et } \\
\text { al. 2009) }\end{array}$} & I forget about time passing while playing the game \\
\hline & I become unaware of my surroundings while playing the game \\
\hline & I temporarily forget worries about everyday life while playing the game \\
\hline & I experience an altered sense of time \\
\hline & I can become involved in the game \\
\hline & I feel emotionally involved in the game \\
\hline \multirow{7}{*}{$\begin{array}{l}\text { Enjoyment } \\
\text { (Adapted from Feng } \\
\text { et al. 2008) }\end{array}$} & I feel unhappy when playing Quick Quiz. \\
\hline & I feel worried when playing Quick Quiz. \\
\hline & I feel happy when playing Quick Quiz. \\
\hline & I feel exhausted when playing Quick Quiz. \\
\hline & I feel miserable when playing Quick Quiz. \\
\hline & I talk to myself when playing Quick Quiz. \\
\hline & I make loud comments even if nobody is around when playing Quick Quiz. \\
\hline \multirow{6}{*}{$\begin{array}{l}\text { Social Interaction } \\
\text { (Adapted from Fu et } \\
\text { al. 2009) }\end{array}$} & I felt cooperative toward other classmates \\
\hline & I strongly collaborated with other classmates \\
\hline & The cooperation in Quick Quiz is helpful to my learning \\
\hline & Quick Quiz supports a social interaction between the players \\
\hline & Quick Quiz supports communities within the game \\
\hline & Quick Quiz supports communities outside the game \\
\hline \multirow{5}{*}{$\begin{array}{l}\text { Experience } \\
\text { (Adapted from } \\
\text { Bourgonjon et al. } \\
\text { 2010) }\end{array}$} & I like playing video games. \\
\hline & I often play video games. \\
\hline & Compared to people of my age, I play a lot of video games. \\
\hline & I would describe myself as a gamer. \\
\hline & I play different types of video games. \\
\hline \multirow[t]{2}{*}{ Ease of Use } & I knew how to handle Quick Quiz in the classroom \\
\hline & It was easy for me to use Quick Quiz the classroom \\
\hline
\end{tabular}


\begin{tabular}{|l|l} 
(Adapted from & My interaction with Quick Quiz in the classroom was clear and
\end{tabular}

Bourgonjon et al.

understandable

2010)

Copyright: () 2018 Filippou, Cheong \& Cheong. This is an open-access article distributed under the terms of the Creative Commons Attribution-NonCommercial 3.0 Australia License, which permits non-commercial use, distribution, and reproduction in any medium, provided the original author and AJIS are credited.

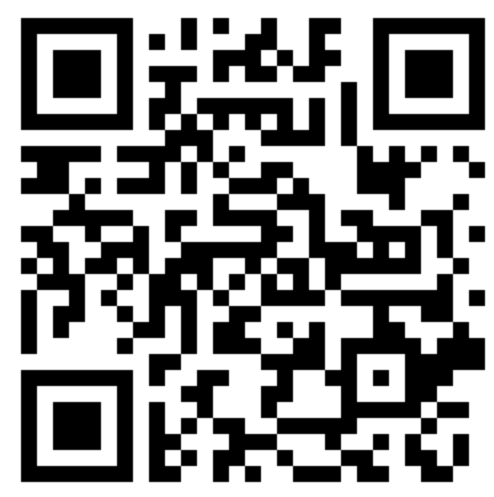

